\title{
Tolerance of four spring barley (Hordeum vulgare) varieties to weed harrowing
}

\author{
P K HANSEN*, I A RASMUSSEN*, N HOLST* \& C ANDREASEN $\dagger$ \\ *Department of Integrated Pest Management, Faculty of Agricultural Sciences, University of Aarhus, Research Centre Flakkebjerg, Slagelse, \\ Denmark, and †Department of Agricultural Sciences, Faculty of Life Sciences, University of Copenhagen, Taastrup, Denmark
}

Received 28 August 2006

Revised version accepted 8 March 2007

\section{Summary}

We investigated the tolerance to weed harrowing of four spring barley varieties and examined the possible interactions between varietal weed suppressive ability and two nutrient levels. Tolerance was defined as the combined effect of crop resistance (ability to resist soil covering) and crop recovery (the ability to recover in terms of yield). The weed harrowing strategy was a combination of one pre- and one post-emergence weed harrowing. In terms of yield, the four varieties responded significantly differently to weed harrowing and the response depended on nutrient level. At the lower nutrient level, weed harrowing caused an increase in yield of $4.4 \mathrm{hkg} \mathrm{ha}^{-1}$ for a strong competitor (cv. Otira), while there was no effect on yield at the higher nutrient level. For a weaker competitor (cv. Brazil), weed harrowing caused no change in yield at the lower nutrient level, whereas yield decreased by $6.0 \mathrm{hkg} \mathrm{ha}^{-1}$ at the higher nutrient level. There were marked differences between the weed suppressive ability of the four varieties when not harrowed, with less pronounced but significant differences when harrowed. Weed harrowing did not change the weed suppressive ability of a variety. Varieties that are tall at post-emergence harrowing and have increased density after pre-emergence harrowing, are the ones that benefit most from weed harrowing.

Keywords: cereal varieties, image analysis, mechanical weed control, spring barley cultivars, weed competition.

Hansen PK, Rasmussen IA, Holst N \& Andreasen C (2007). Tolerance of four spring barley (Hordeum vulgare) varieties to weed harrowing. Weed Research 47, 241-251.

\section{Introduction}

Weed management in organic or low-input growing systems relies on the integration of preventive and curative methods (Barberi, 2002). Preventive methods like crop rotation (Bond \& Grundy, 2001), fertiliser placement (Rasmussen, 2002) and use of competitive species and varieties (Lemerle et al., 2001) can keep weed populations at a manageable level within the growing system as a whole, while curative methods like pre- and post-emergence weed harrowing (Rasmussen, 1991) are required to control weeds when thresholds are exceeded. The spring tines of the harrow control weeds by uprooting and/or covering small weed plants with soil (Kurstjens \& Kropff, 2001).

Pre- and post-emergence weed harrowing is often used in combination in organically grown spring cereals.
Timing is important for the success of pre-emergence weed harrowing, because it should be conducted just before crop emergence to ensure effective weed control without harming the crop (Rasmussen \& Rasmussen, 1999). The efficacy of post-emergence weed harrowing relies on its selectivity, which has been defined as the ratio between the positive weed control effect and the negative crop cover effect (Rasmussen, 1992). If the weed plants are large relative to the crop plants, selectivity is reduced and the risk of damaging the crop mechanically or by soil coverage is increased (Rasmussen, 1991). The risk of crop damage also rises with the intensity of weed control, which is determined by the speed or aggresivity of the spring tines (Kurstjens \& Kropff, 2001). Crop damage due to weed harrowing has been shown to reduce yield (Kirkland, 1994; Rasmussen \& Svenningsen, 1995; Jensen et al., 2004). Apart from

Correspondence: P K Hansen, Department of Integrated Pest Management, Faculty of Agricultural Sciences, University of Aarhus, Research Centre Flakkebjerg, DK-4200 Slagelse, Denmark. Tel: (+45) 899935 97; Fax: (+45) 899935 00; E-mail: prebenk.hansen@agrsci.dk 
the direct effect on yield through changes in crop growth, indirect effects on crop-weed competition from altered conditions may be important.

Tolerance to weed harrowing has been defined as the combined characteristics of the crop to resist initial damage caused by weed harrowing and to recover from this damage (Gundersen et al., 2006). Resistance to initial damage is related to the height of the crop and the flexibility and shape of the leaves (Kurstjens \& Perdok, 2000). Kurstjens and Kropff (2001) found that uprooting was important for the resistance of the crops, Lolium perenne L., Lepidium sativum L. and Chenopodium quinoa Willd. However, for strongly anchored plants, like cereals, soil covering is likely to be more important than uprooting. A crop with high recovery is characterised by growth traits well-suited to overcome soil covering and maintain yield. The degree of recovery from soil covering depends on burial depth, soil texture and plant recovery processes (Baerveldt \& Ascard, 1999; Kurstjens \& Kropff, 2001).

Lemerle et al. (2001) described several studies showing strong varietal differences in weed suppression. The majority of these studies have been conducted as a comparison between weedy and weed-free (herbicidetreated) conditions. Only a few studies have been conducted to estimate varietal differences in response to weed harrowing in cereals and to study if weed harrowing interacts with weed suppressive ability. Rasmussen et al. (2004) measured tolerance in spring barley (Hordeum vulgare L.) as the relative reduction in yield and found tolerance was negatively correlated with growth traits associated with weed suppressive ability.

The aim of this study was to investigate the tolerance of four spring barley varieties to weed harrowing under organic growing conditions at two nutrient levels. The weed harrowing strategy was a combination of one preand one post-emergence weed harrowing, as described by Rasmussen and Rasmussen (1995). We estimated the effect of weed harrowing (i) on soil covering of the crop just after harrowing, (ii) on yield and investigated (iii) the possible interactions among variety, weed harrowing and weed suppression.

\section{Materials and methods}

\section{Experimental conditions}

Four varieties of spring barley were chosen to represent the range in varietal weed suppressiveness among varieties in the Danish variety list (Anon, 2005c). The weed suppressive index (SI) of the varieties was 0.75, 0.91, 0.98 and 1.04 for Modena, Orthega, Otira and Brazil respectively (Hansen $e t$ al., 2006). SI indicates the expected relative amount of weed cover, where 1.00 equals an average variety. Suppressive varieties have lower SI values, and Modena was expected to be the most suppressive variety and Brazil the least.

The varieties were studied in field trials at Research Centre Flakkebjerg $\left(55^{\circ} 19^{\prime} \mathrm{N}, 11^{\circ} 24^{\prime} \mathrm{E}\right)$ in 2004 and 2005 on sandy loam containing $12.4 \%$ clay, $60.1 \%$ silt, $25.5 \%$ sand and $2.0 \%$ organic matter. In 2004 and 2005, the precipitation from sowing to harvest was $283 \mathrm{~mm}$ and $207 \mathrm{~mm}$ respectively. Despite the greater precipitation in 2004, spring was characterised as being drier than in 2005. Growing day degrees $\left(\mathrm{d}^{\circ} \mathrm{C}\right)$, accumulated from the date of sowing with a base temperature of $0^{\circ} \mathrm{C}$, was used as timescale. The interval from sowing to harvest was $1724 \mathrm{~d}^{\circ} \mathrm{C}$ in 2004 and $1660 \mathrm{~d}^{\circ} \mathrm{C}$ in 2005 . The crop rotation of the experimental areas is shown in Table 1. The soil was mouldboard ploughed to a depth of $25 \mathrm{~cm}$ in late autumn.

The field trials were split-plot designs. Whole plots consisted of the eight combinations of three factors; two levels each of herbicides $( \pm)$, weed harrowing $( \pm)$, and nutrient level $(40 \%$ or $80 \%$ of the recommended nitrogen need) (Anon, 2003). The eight subplots were arranged in two neighbouring rows with four subplots per row. Each subplot consisted of the four varieties in pure stands, three two-component mixtures and one three-component mixture of the varieties. The mixtures were not considered but were included in the primary statistical analysis to adjust for experimental design. An $\alpha$-design was used to optimise the comparisons between varieties within whole plots (Patterson \& Williams, 1976). With three replicates, there were 192 plots each year.

The gross plot size was $2.5 \times 14.5 \mathrm{~m}^{2}$ and the net plot size was $1.50 \times 12.0 \mathrm{~m}^{2}$. The net plots were split into a part used for non-destructive measurements and combine harvesting $\left(1.5 \times 9.5 \mathrm{~m}^{2}\right)$ and a part used for destructive measurements $\left(1.5 \times 2.5 \mathrm{~m}^{2}\right)$.

The crop was sown with a seed drill with $12.0 \mathrm{~cm}$ row width on 15 April 2004 and 13 April 2005. Seed rates

Table 1 Crop rotation in experimental fields prior to experiment

\begin{tabular}{lll}
\hline Year & 2004 & 2005 \\
\hline 2000 & $\begin{array}{l}\text { Oats (Avena sativa L.) } \\
\text { Spring barley with white } \\
\text { clover (Trifolium repens L.) } \\
\text { under sown }\end{array}$ & $\begin{array}{c}\text { Lucerne (Medicago } \\
\text { sativa L.) }\end{array}$ \\
2002 & $\begin{array}{c}\text { White clover for seed } \\
\text { production }\end{array}$ & Lucerne \\
2003 & $\begin{array}{c}\text { Winter rape (Brassica } \\
\text { napus ssp. napus L.) }\end{array}$ & Oats \\
2004 & $\begin{array}{c}\text { Spring barley, experiment } \\
2005\end{array}$ & $\begin{array}{c}\text { Winter wheat (Triticum } \\
\text { aestivum L.) }\end{array}$ \\
& & Spring barley, experiment
\end{tabular}


were adjusted for seed weights and germination rates to give a population of 350 plants $\mathrm{m}^{-2}$. As model weeds, we used a mixture of $25 \%$ viable seeds of Chenopodium album L., 25\% Phacelia tanacetifolia Benth., 25\% Brassica napus ssp. napus L. and 25\% Trifolium incarnatum L. cv. Poppelsdorfer in plots with no pesticide treatments. The weeds were sown on 16 April 2004 and 13 April 2005 at a density of 200 seeds $\mathrm{m}^{-2}$. The naturally occurring weeds were Stellaria media (L.) Vill., Sinapsis arvensis L., Viola arvensis Murray, Veronica arvensis L., Thlaspi arvense L. and Polygonum convolvulus $\mathrm{L}$.. The total density of these species did not exceed 50 plants $\mathrm{m}^{-2}$ and the biomass of these species was included in the total weed biomass. Due to heterogeneous infestations of Cirsium arvense (L.) Scop. in the experiments, the density of this species was recorded on 6 July $2004\left(992 \mathrm{~d}^{\circ} \mathrm{C}\right)$ and 1 August $2005\left(1435 \mathrm{~d}{ }^{\circ} \mathrm{C}\right)$.

In the herbicide-treated plots, we applied a mixture of $7.5 \mathrm{~g}$ tribenuron-methyl $\mathrm{ha}^{-1}$ (Express ST, $500 \mathrm{~g}$ a.i. $\mathrm{kg}^{-1}$; DuPont Danmark Aps, Copenhagen, Denmark), $108 \mathrm{~g}$ fluroxypyr ha ${ }^{-1}$ (Starane 180, $180 \mathrm{~g}$ a.i. $\mathrm{L}^{-1}$; Dow AgroSciences Danmark A/S, Copenhagen, Denmark) and $150 \mathrm{~g}$ surfactant $\mathrm{ha}^{-1}$ (Lissapol Bio, $1000 \mathrm{~g}$ a.i. $\mathrm{L}^{-1}$; Syngenta Crop Protection A/S, Copenhagen, Denmark) on 12 May $2004\left(310 \mathrm{~d}{ }^{\circ} \mathrm{C}\right)$. In 2005 (13 May 2005, $265 \mathrm{~d}^{\circ} \mathrm{C}$ ) we applied a mixture of $24 \mathrm{~g}$ ioxynil $+24 \mathrm{~g}$ bromoxynil ha ${ }^{-1}$ (Oxitril CM, $200 \mathrm{~g}+200 \mathrm{~g}$ a.i. $\mathrm{L}^{-1}$; Bayer CropScience, Copenhagen, Denmark), $0.0255 \mathrm{~g}$ mefenpyr-diethyl ha ${ }^{-1}+0.0085$ g iodosulfuron-methyl$\mathrm{Na} \mathrm{ha}{ }^{-1}$ (Hussar, $150+50 \mathrm{~g}$ a.i. $\mathrm{kg}^{-1}$; Bayer CropScience) $+400 \mathrm{~g}$ surfactant $\mathrm{ha}^{-1}$ (Isoblette, $1000 \mathrm{~g}$ a.i. $\mathrm{L}^{-1}$; Bayer CropScience). The applications were performed at a dosage of $150 \mathrm{~L} \mathrm{ha}^{-1}$ with nozzle type SISO-LD-02-110 (Hardi International, Helgeshøj Allé 38, Taastrup, Denmark) and a pressure of $230 \mathrm{kPa}$. Driving speed was $6 \mathrm{~km} \mathrm{~h}^{-1}$. All dosages and mixtures were determined using the decision support system Crop Protection Online (Anon, 2005b). We assumed no interactions between herbicide treatments and the growth and development of the varieties.

One pre-emergence weed harrowing was conducted on 25 April $2004\left(129 \mathrm{~d}{ }^{\circ} \mathrm{C}\right)$ and 21 April $2005\left(79 \mathrm{~d}^{\circ} \mathrm{C}\right)$. The driving speed was approximately $9 \mathrm{~km} \mathrm{~h}^{-1}$. On 13 May $2004\left[319 \mathrm{~d}{ }^{\circ} \mathrm{C}\right.$, crop growth stage (GS) 21-22 (Lancashire et al., 1991)] and 17 May $2005\left(300 \mathrm{~d}^{\circ} \mathrm{C}\right.$, crop GS 21-25) one post-emergence weed harrowing was conducted with a driving speed of approximately 7-8 $\mathrm{km} \mathrm{h}^{-1}$. The weeds were between cotyledon stage to four true leaves. The intensity of harrowing was adjusted by driving speed in an attempt not to exceed an average of $20 \%$ crop burial at the post-emergence weed harrowing. Weed harrowing was carried out with a spring-tine harrow (Einböck, Dorf an der Pram, Austria). The postemergence weed harrowing in 2004 was carried out on humid soil, while the soil was dry on the surface in 2005 . In both years, pre- and the post-emergence weed harrowing were conducted under sunny and windy conditions resulting in fast drying of the soil.

\section{Measurements}

Tolerance to weed harrowing was measured as an immediate effect (area of plants covered with soil just after weed harrowing) and a long-term effect (yield). To estimate the degree of soil cover, two digital images were acquired twice weekly in every plot from crop emergence until 3 weeks after the post-emergence weed harrowing; subsequently, images were acquired weekly. Extra photographs were acquired immediately prior to the post-emergence weed harrowing. We used a Canon PowerShot G1 Camera. The exact positions of the images in the plots were marked to ensure that images were acquired at the same spot every time. The camera was mounted on a stand covered with white sheet clothing, to provide diffuse lighting conditions and to eliminate shadows and highlighted areas. The camera height was approximately $133 \mathrm{~cm}$ above the soil surface. The resolution of the images was $2086 \times 1548$ pixels, and they covered approximately $450 \times 350 \mathrm{~mm}$ on the soil surface. Thus each pixel covered $0.22 \times 0.22 \mathrm{~mm}$ soil surface. The camera set focus, ISO speed, white balance and shutter speed automatically. Images were saved as Canon RAW format, and converted to 24-bit PPM format with the free-ware program DCRAW.EXE (Anon, 2005a). Images were loaded into MATLAB 6.5 (Anon, 2002) as RGB images and were converted to 8-bit greyscale images to make the green pixels more pronounced by using a slightly modified version of the algorithm described by Woebbecke et al. (1995):

$$
g_{x, y}=2 G_{x, y}-R_{x, y}-B_{x, y}
$$

where $g_{x, y}$ is the greyscale value of a pixel at position $(x, y)$ in the image. $R, G$ and $B$ are non-normalised values from the red, green and blue channel respectively. To segment the pixels with high intensity (former green) from pixels with low intensity (former non-green), a modified version of an automatic thresholding technique was used, which chose the threshold to minimise the intra-class variance between green and non-green pixels (Otsu, 1979). After thresholding, a median filter was applied to reduce 'salt-and-pepper noise'. Vegetation cover $(V C ; \%)$ was estimated in every image as the relation between the number of vegetation pixels and the total number of pixels in the binary images. Weed harrowing covered the leaves with soil, which was measured as the difference between $V C$ just before and just after harrowing ( $\triangle V C$; percentage point).

Canopy height $(H ; \mathrm{cm})$ was measured in the same positions as the images in the herbicide-treated, non- 
harrowed plots on 19 May $2004\left(386 \mathrm{~d}^{\circ} \mathrm{C}\right)$ and 25 May $2005\left(396 \mathrm{~d}{ }^{\circ} \mathrm{C}\right)$ with a circular plate divided into four quarters. The plate had an area of $0.25 \mathrm{~m}^{2}$ and was mounted on a measuring stick. The canopy height was defined as the vertical distance from soil surface to the underside of the plate when at least one leaf touched each of the four quarters of the plate.

Leaf area index (LAI; $\mathrm{m}^{2}$ leaf area per $\mathrm{m}^{2}$ ground area) was measured on 8 June $2004\left(613 \mathrm{~d}^{\circ} \mathrm{C}\right)$ and 1 June 2005 $\left(496 \mathrm{~d}^{\circ} \mathrm{C}\right)$. We measured twice in the same positions as the images and canopy heights, using LICOR 2000 Canopy Analyzer (LI-COR Biosciences, Lincoln, NE, USA) (Lang et al., 1985; Welles \& Norman, 1991).

Weed biomass $\left(\mathrm{DM}_{\mathrm{W}} ; \mathrm{g} \mathrm{m}^{-2}\right)$ was measured on 11 June $2004\left(659 \mathrm{~d}^{\circ} \mathrm{C}\right.$, crop GS 41-43) and 15 June 2005 (659 $\mathrm{d}^{\circ} \mathrm{C}$, crop GS 41-49) in all plots by cutting the plant material at the soil surface in a square $0.25 \mathrm{~m}^{2}$ frame. The plant material was separated into crop and weeds. The samples were dried at $100^{\circ} \mathrm{C}$ for $24 \mathrm{~h}$ and dry matter was measured. The interval in $\mathrm{d}{ }^{\circ} \mathrm{C}$ between postemergence weed harrowing and biomass measurement was $659-319=340 \mathrm{~d}^{\circ} \mathrm{C}$ in 2004 and $659-300=$ $359 \mathrm{~d}{ }^{\circ} \mathrm{C}$ in 2005. The experiments were harvested on 19 August 2004 and 16 August 2005 with a combine plot harvester and the yield $\left(Y ; \mathrm{hkg} \mathrm{ha}^{-1}\right)$ was adjusted to $85 \%$ dry matter.

Crop density $\left(D_{\mathrm{C}}\right.$; plants $\left.\mathrm{m}^{-2}\right)$ was recorded before post-emergence harrowing on 4 May $2004\left(207 \mathrm{~d}^{\circ} \mathrm{C}\right)$ and 11 May $2005\left(247 \mathrm{~d}^{\circ} \mathrm{C}\right)$ as the number of crop plants in 1$\mathrm{m}$ crop row replicated three times randomly in every plot.

\section{Statistics}

To adjust for experimental design and inhomogeneous presence of $C$. arvense, $\Delta V C, D_{\mathrm{C}}, D M_{W}$ and $Y$ were analysed with the following model:

$$
\begin{aligned}
X_{\text {grcnhmv }}= & \mu+\alpha_{n}+\beta_{h}+\gamma_{m}+\delta_{v} \\
& +[\text { all two-factor interactions }] \\
& +[\text { all three-factor interactions }] \\
& +[\text { the four-factor interaction }]+J t_{\text {grcnhmv }} \\
& +E_{g}+F_{g n h m}+G_{g r}+H_{g c}+I_{g r c n h m v}
\end{aligned}
$$

where $X_{\text {grcnhmv }}$ is the response $\left(\Delta V C, D_{\mathrm{C}}, D M_{W}, L A I\right.$ and $Y$ ) recorded for variety $v$ (regarding each variety mixture as a 'variety'), in replicate $g$ and treated with nutrient level $n$, herbicide level $h$ and weed harrowing level $m$ (and located in row $r$ and column $c$ ). $J t_{\text {grcnhmv }}$ is the density of $C$. arvense, which was considered as a random covariate. $E_{g}$ is the random effect of replicate $g . F_{g n h m}$ is the random effect of the whole plot with treatment combination $\mathrm{nhm}$ in replicate $g . G_{g r}$ is the random effect of the incomplete block $r$ (in the $\alpha$-design) in replicate $g . H_{g c}$ is the random effect of column $c$ in replicate $g$, and $I_{\text {grchmv }}$ is the residual variance, which is considered randomly distributed. We assumed all random effects to be normally distributed with mean zero and constant variances: $\sigma_{E}^{2}, \sigma_{F}^{2}, \sigma_{G}^{2}, \sigma_{H}^{2}, \sigma_{I}^{2}$. Greek letters indicate systematic effects. The two years were analysed individually and statistical analyses were carried out by the maximum likelihood method in the mixed linear model procedure (PROC MIXED) (SAS Institute Inc., 1999). To ensure variance stability, $V C$ was logit transformed and $D M_{W}$ was square root transformed. For $L A I, Y$ and $\Delta V C$ no transformation was necessary. Based on the model parameters we estimated yield, change in vegetation cover, LAI, crop density and weed biomass for each plot by the following model:

$$
\begin{aligned}
\hat{X}_{n h m v g}= & \hat{\mu}+\hat{\alpha}_{n}+\widehat{\beta}_{h}+\widehat{\gamma}_{m}+\widehat{\delta}_{v} \\
& +[\text { all two-factor interactions }] \\
& +[\text { all three-factor interactions }] \\
& +[\text { the four-factor interaction }]+\widehat{I}_{g r c n h m v}
\end{aligned}
$$

where $\widehat{X}_{\text {nhmvg }}$ is the response $\left(\widehat{Y}_{\text {nhmvg }}, \widehat{\mathrm{DM}}_{\text {Whhmvg }}\right.$, $\widehat{\Delta \mathrm{VC}}_{n h m v g}, \widehat{\mathrm{LAI}}_{n h m v g}, \widehat{D}_{\text {Cnhmvg }}$ ) for each treatment and replicate adjusted for experimental design and presence of C. arvense. $\hat{\mu}, \widehat{\alpha}_{n}, \widehat{\beta}_{h}, \widehat{\gamma}_{m}, \widehat{\delta}_{v}$ and $\widehat{I}_{\text {grcnhmv }}$ indicate the estimated parameter values for $\mu, \alpha_{n}, \beta_{h}, \gamma_{m}, \delta_{v}$ and $I_{g r c h m v}$ from Eqn (2). We excluded all data from variety mixtures and used the estimates in all further analyses.

The effect of weed harrowing in combination with the varietal weed suppressive ability on the weed biomass was estimated by

$$
\Delta W_{n v g}=\widehat{\mathrm{DM}}_{W h h-m+v g}-\widehat{\mathrm{DM}}_{W h h-m-v g}
$$

where $\Delta W_{n v g}$ corresponds to the absolute reduction in weed biomass after harrowing in replicate $g$ and variety $v$ at nutrient level $n, h$ - indicates herbicide untreated plots, $m+$ indicates weed harrowed plots and $m-$ indicates mechanically untreated plots. The effect of mechanical weed control on yield were estimated by

$$
\Delta Y_{n v g}=\widehat{Y}_{n h+m+v g}-\widehat{Y}_{n h+m-v g}
$$

where $\Delta Y_{n v g}$ corresponds to the absolute yield reduction due to harrowing, $h+$ indicates herbicide treated plots (assuming no influence from weeds), and the other indices are as described above.

As there were significant treatment effects on crop density after pre-emergence harrowing, we estimated the difference in crop density between pre-emergence harrowed and non-harrowed plots by the following model:

$$
\Delta D_{C n v g}=\widehat{D}_{C n h m+v g}-\widehat{D}_{C n h m-v g}
$$

where $\Delta D_{\text {Cnvg }}$ indicates the difference in crop density due to pre-emergence harrowing, $m+$ indicates harrowed plots, $m$ - indicates non-harrowed plots, and the other indices are as described above. 
These estimated values were used in the following analysis with a mixed linear model, which was common for the two years:

$$
\Delta X_{n v y g}=\mu^{\prime}+\alpha_{n}^{\prime}+\delta_{v}^{\prime}+\phi_{y}+\varphi_{n v}+\eta_{n y}+l_{v y}+\kappa_{n v y}+K_{n v y g}
$$

where $\Delta X_{n v g}$ is the response (either $\Delta Y_{n v g}, \Delta W_{n v g}, \Delta V C_{n v g}$ or $L A I_{n v g}$ ) and $\alpha_{n}^{\prime}$ is the effect of nutrient level, $\delta_{v}^{\prime}$ is the effect of variety, $\phi_{y}$ is the effect of year, $\varphi_{n v}$ is the interaction between variety and nutrient level, $\eta_{n y}$ is the interaction between nutrient level and year, $l_{v y}$ is the interaction between variety and year, $\kappa_{n v y}$ is the threeway interaction and $K_{n v g y}$ is the residual variance which is assumed random and normally distributed with a constant variance of $\sigma_{K}^{2}$.

Finally, we analysed if $\Delta V C$ or $\Delta D$ could explain the varietal differences in weed biomass and yield. We used data from plots with mechanical weed control but without herbicide treatment and analysed it with the following model:

$\widehat{X}_{n v g m+h-y}=\mu^{*}+\alpha_{n}^{*}+\beta_{y}^{*}+\chi_{n y}^{*}+\delta^{*}(Z)_{n v g m+h-y}+E_{n v g m+h-y}^{*}$

where $\widehat{X}_{n v g m+h-y}$ is the response variable (either $\widehat{W}_{n v g m+h-y}$ or $\left.\widehat{Y}_{n v g m+h-y}\right), \alpha^{*}$ is the effect of nutrient level, $\beta^{*}$ is the effect of year, $\chi^{*}$ is the effect of the interaction between nutrient level and year $\delta^{*}$ is the effect of $Z$ (either $\Delta V C$ or $\Delta D$ ) used as a covariate, and $E_{n v g m+h-y}^{*}$ is the error which is considered random and normally distributed.

\section{Results}

Crop density $\left(D_{\mathrm{C}}\right)$ was measured before post-emergence weed harrowing and could thus only be affected by the pre-emergence harrowing. Measurements conducted after post-emergence harrowing comprising weed biomass $\left(D M_{W} / \Delta W\right)$, change in vegetation cover $(\Delta V C)$ and yield $(Y / \Delta Y)$, reflect the combined effect of both harrowings. Vegetation cover $(V C)$ was measured after both pre- and post-emergence harrowing.

The varieties differed significantly in canopy height with similar patterns in both years, Modena and Brazil achieving the largest and smallest final height respectively (Table 2 ).

\section{Effect of pre-emergence weed harrowing on vegetation cover and density}

Pre-emergence weed harrowing reduced vegetation cover $(V C$; measured just before post-emergence weed harrowing) at the high nutrient level in herbicide-treated plots $(P=0.0165)$, from $39 \%$ in the non-harrowed to $35 \%$ in the harrowed plots (average of the two years),
Table 2 Canopy height ( $H ; 1$ week after post-emergence harrowing and final) and leaf area index (LAI; final)

\begin{tabular}{|c|c|c|c|c|c|c|}
\hline \multirow[b]{3}{*}{ Variety } & \multicolumn{4}{|c|}{ Canopy height; $H$ (cm) } & \multirow{2}{*}{\multicolumn{2}{|c|}{ LAI }} \\
\hline & \multicolumn{2}{|l|}{2004} & \multicolumn{2}{|l|}{2005} & & \\
\hline & 19 May & Final & 24 May & Final & 2004 & 2005 \\
\hline Modena & $17(0.5)$ & $92(1.3)$ & $20(0.9)$ & $97(1.7)$ & $4.1(0.1)$ & $3.4(0.1)$ \\
\hline Otira & $14(0.6)$ & $81(1.3)$ & $15(0.9)$ & 79 (1.8) & $4.7(0.1)$ & $3.4(0.1)$ \\
\hline Orthega & $18(0.5)$ & 79 (1.3) & $21(0.9)$ & $82(1.7)$ & $4.2(0.1)$ & $3.1(0.1)$ \\
\hline Brazil & $14(0.6)$ & 76 (1.3) & $13(0.9)$ & $74(1.8)$ & $3.9(0.1)$ & $2.4(0.1)$ \\
\hline
\end{tabular}

Average (standard error) of both nutrient levels.

while the low nutrient treatment had an average of $34 \%$, irrespective of weed harrowing (Fig. 1). There was a strong additive effect of variety on $V C$, as variety did not interact with the other treatments.

Surprisingly, pre-emergence weed harrowing increased the crop density $\left(D_{\mathrm{C}}\right)$ of Modena and Brazil in both years and under both nutrient levels, by 26 and 25 plants $\mathrm{m}^{-2}$, respectively, averaged over all other factors (Fig. 2). For Otira, $D_{\mathrm{C}}$ was reduced by 11 plants $\mathrm{m}^{-2}$ on average by weed harrowing at the high nutrient level, while there was no significant difference at low nutrient levels. Pre-emergence weed harrowing had a negative effect on $D_{\mathrm{C}}$ for Orthega in 2004 (13 plants $\mathrm{m}^{-2}$ less) while in 2005 the opposite occurred (32 plants $\mathrm{m}^{-2}$ more).

\section{Effects of post-emergence weed harrowing on vegetation cover and $L A I$}

The change in vegetation cover $(\Delta V C)$ caused by postemergence weed harrowing was analysed by Eqn (7) for differences between the varieties in the herbicide-treated plots. There was a very strong effect of variety $(P<0.0001)$ and year $(P<0.0001)$. We found significant effects of the interaction between nutrient level and year $(P=0.039)$. Orthega was covered less by harrowing than other varieties. We found only a $7 \%$ reduction in this variety compared with Otira, where the reduction was more than the double $(15 \%)$. In herbicide-untreated plots, $\Delta V C$ represents the reduction in the sum of vegetation cover of both weeds and crop. There were only slight differences in the levels of $\Delta V C$, whether weeds were present or not, indicating that the main differences in $\triangle V C$ were caused by differences in crop cover (Table 3). We found a significant negative correlation between $\triangle V C$ and canopy height measured 6 days after weed harrowing in 2004 (low nutrient level, $P<0.001$; high nutrient level, $P=0.007)$. In 2005, there was no significant correlation (Fig. 3).

Leaf area index measured in the herbicide-treated, non-harrowed plots approximately 2 weeks after the post-emergence weed harrowing showed a strong 
2004
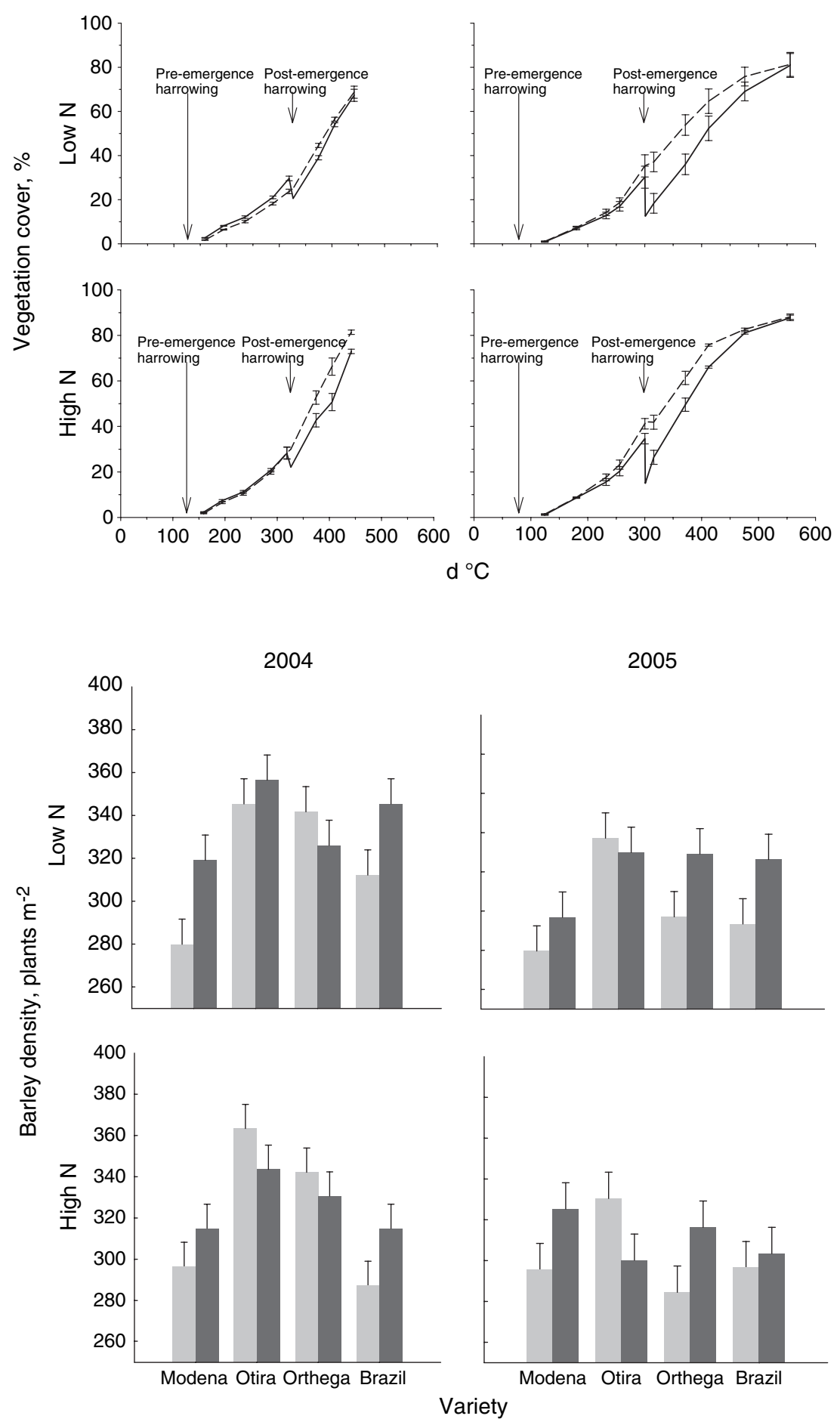

Fig. 1 Development of vegetation cover $(V C)$ exemplified by $c v$. Brazil under the low nutrient level (upper) and the high nutrient level (lower) in herbicide-treated plots in 2004 (left) and 2005 (right). The solid lines show weed harrowed plots and the broken lines show non-harrowed plots. Vertical lines show standard errors.
Fig. 2 Crop plant density adjusted for experimental design, under low (upper) and high (lower) nutrient levels in 2004 (left) and 2005 (right). Light grey bars show nonharrowed plots and dark grey bars show harrowed plots. Vertical lines show standard errors. significant effect of variety Eqn (7), nutrient level and year $(P<0.0001$ for all $)$, but with an interaction between variety and year $(P=0.006)$ and between nutrient level and year (0.01) (Table 2, Fig. 4). For the change in $L A I$ caused by harrowing, there was a significant difference between years, but there were no significant differences between varieties or any varietal interactions. There was no significant effect of weed harrowing on LAI in 2004, while in 2005 harrowing caused a $9.3 \%$ reduction in $L A I$.

Due to the differences in crop density induced by the varietal differences in response to pre-emergence harrowing, $\Delta D$ was used as a covariate in the analysis, which gave a significant improvement of the model Eqn (8). The slope of $\Delta D$ was 0.000263 , which means that an increase caused by the pre-emergence weed harrowing of 
Table 3 Change in vegetation cover (percentage points) for herbicide-treated $\Delta \widehat{\mathrm{VC}}_{v h+}$ and untreated plots $\Delta \widehat{\mathrm{VC}}_{v h-}$

\begin{tabular}{lll}
\hline Variety & $\Delta \widehat{\mathrm{VC}}_{v h+}$ & $\Delta \widehat{\mathrm{VC}}_{v h-}$ \\
\hline Modena & $0.10(0.008)$ & $0.12(0.012)$ \\
Otira & $0.15(0.008)$ & $0.12(0.012)$ \\
Orthega & $0.07(0.008)$ & $0.06(0.011)$ \\
Brazil & $0.13(0.009)$ & $0.17(0.011)$ \\
\hline
\end{tabular}

Average over two years (standard error).

1 plant $\mathrm{m}^{-2}$ would result in an increased vegetation cover of $0.026 \%$.

\section{Effects on weed biomass}

In the non-harrowed, herbicide-untreated plots there was significantly more weed biomass in 2005 than in 2004 (Fig. 5). The biomass production differed among the varieties $(P=0.012): 114 \mathrm{~g} \mathrm{~m}^{-2}$ for Orthega, $85.7 \mathrm{~g} \mathrm{~m}^{-2}$ for Brazil, $74.9 \mathrm{~g} \mathrm{~m}^{-2}$ for Modena and $67.3 \mathrm{~g} \mathrm{~m}^{-2}$ for Otira (back-transformed averages over both years). Thus, there was $69 \%$ more weed biomass in non-harrowed and herbicide-untreated plots with Orthega compared with Otira. The only significant interaction was between nutrient level and year $(P=0.032)$.

In the weed-harrowed, herbicide-untreated plots, weed biomass was four times greater in 2005 than in 2004. As for the non-harrowed plots, we found a significant interaction between nutrient level and year; weed biomass was six times greater at the high nutrient level in $2005\left(58 \mathrm{~g} \mathrm{~m}^{-2}\right)$ compared with $2004\left(10 \mathrm{~g} \mathrm{~m}^{-2}\right)$, while at the low nutrient level there was only a three times increase from $2004\left(13.8 \mathrm{~g} \mathrm{~m}^{-2}\right)$ to 2005 $\left(32.8 \mathrm{~g} \mathrm{~m}^{-2}\right)$. We found a significant variety by year interaction (Fig. 5), as the plots seeded to Orthega had a greater amount of weed biomass (relative to plots seeded to other varieties) in 2005 versus 2004, while the opposite was true for Brazil. There were no significant interactions between variety and nutrient level. We tested if $\Delta V C$ or $\Delta D$ could explain some of the variation in weed suppression and found that there was no significant improvement of the statistical model Eqn (8) by adding either $\Delta V C$, or $\Delta D$, or both to the model.

An analysis of $\Delta W$ (from Eqn 7), as well as the relative reduction in weed biomass, showed no significant varietal differences, meaning that weed harrowing did not significantly affect the weed varietal suppressive ability, i.e. strong weed suppressors remained strong after weed harrowing.

\section{Effects on crop yield}

In the herbicide-treated plots without weed harrowing (Fig. 6), there were significant effects of variety $(P<0.0001)$, nutrient level $(P<0.0001)$ and year $(P=0.0026)$, and we found significant interactions between nutrient level and year $(P=0.022)$ and between variety and year $(P=0.002)$. In the herbicide-treated plots with weed harrowing (Fig. 6), we found a significant effect of variety $(P<0.0001)$, year $(P<0.0001)$ and nutrient level $(P=0.007)$, but yields responded differently at different nutrient levels in the two years $(P=0.0004)$. In 2004 , there was no significant difference between the nutrient levels. In 2005, there was a strong significant difference with $7.1 \mathrm{hkg} \mathrm{ha}^{-1}$ increase from the low to the high nutrient level (Fig. 6).
Fig. 3 Relationship between canopy height, $H$ and $\Delta V C$ under low (upper) and high (lower) nutrient levels in 2004 (left) and 2005 (right). Each point represents one plot. Low nutrients 2004: $34.2-1.9 H$ $\left(r^{2}=0.69\right)$. Low nutrients 2005: $25.5-0.6 H\left(r^{2}=0.14\right)$. High nutrients 2004: $24.0-1.2 H\left(r^{2}=0.53\right)$. High nutrients 2005: $31.5-0.07 H\left(r^{2}=0.26\right)$.
2004

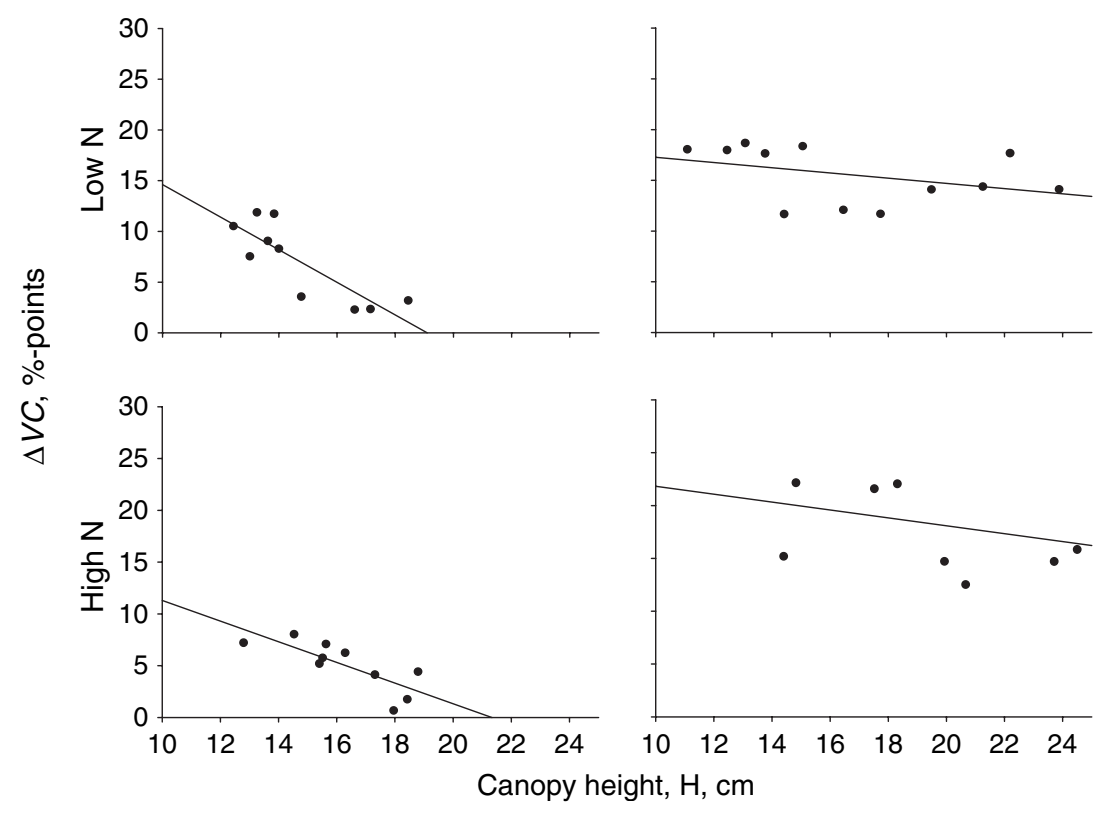


2004

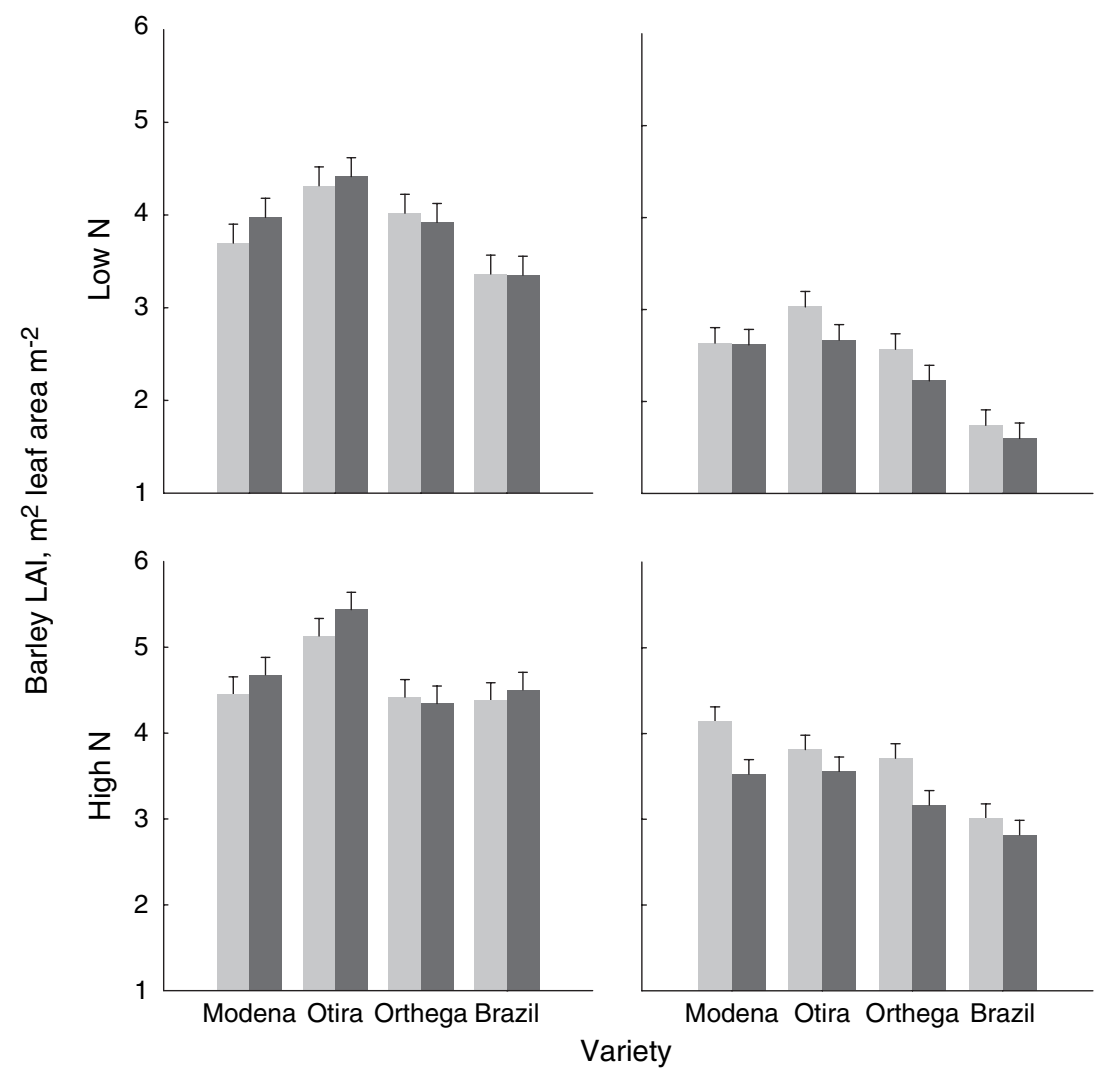

2004

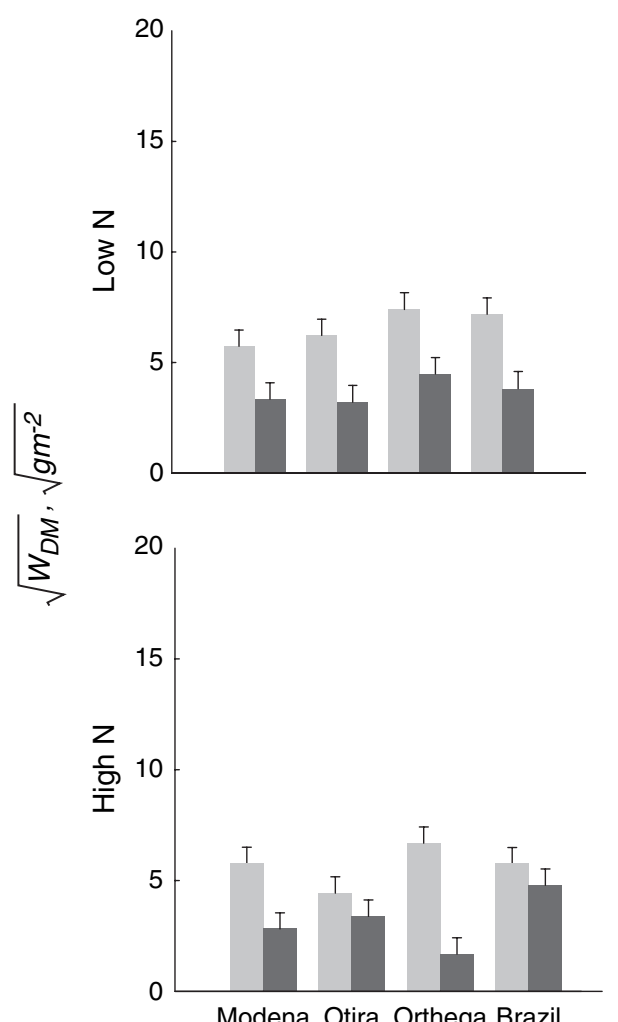

Modena Otira Orthega Brazil
2005
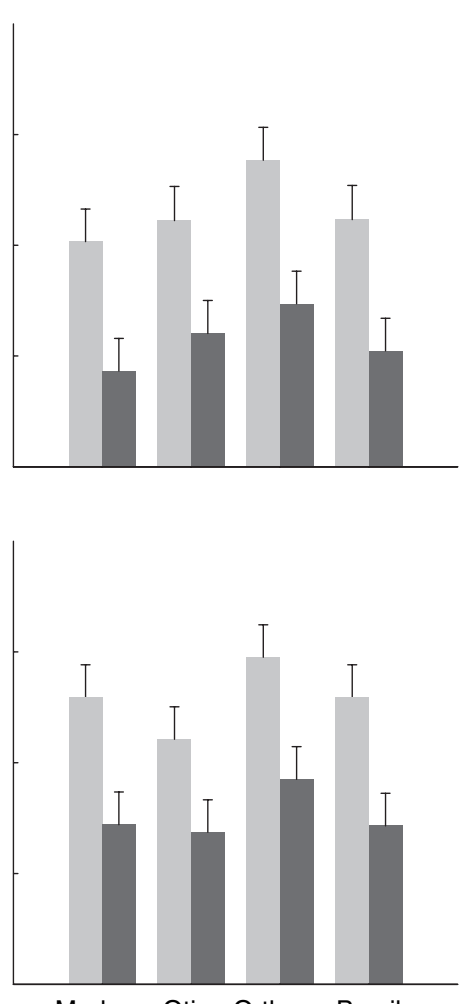

Modena Otira Orthega Brazil

Variety

Fig. 5 Square root transformed weed biomass adjusted for experimental design in herbicide untreated plots under low (upper) and high (lower) nutrient levels in 2004 (left) and 2005 (right). Light grey bars show non-harrowed plots and dark grey bars show harrowed plots. Vertical lines show standard errors. 
Fig. 6 Yield of the varieties in 2004 and 2005 under low (upper) and high (lower) nutrient levels in 2004 (left) and 2005 (right) in herbicide-treated plots. Light grey bars show non-harrowed plots and dark grey bars show harrowed plots. White bars show barley yields from weedy plots. Vertical lines show standard errors.

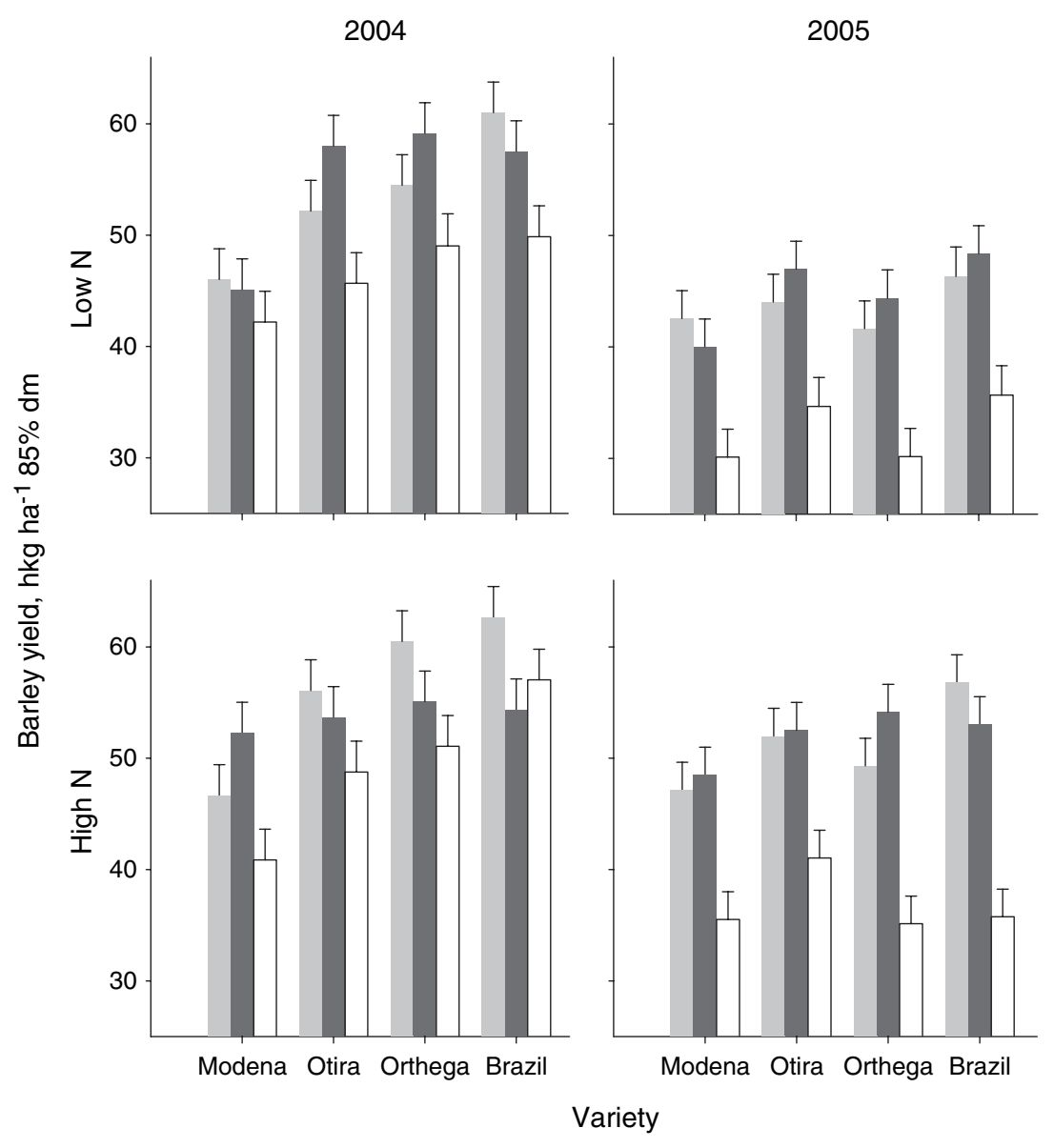

We found a tendency for interaction between variety and nutrient level in the herbicide-treated plots that were harrowed $(P=0.068)$. This was caused by the relatively much greater yield response of Modena to the high nutrient level treatment in comparison with the other varieties.

The estimated yield difference between harrowed and unharrowed treatments Eqn (5) (light grey bars minus dark grey bars in Fig. 6) showed a strong tendency for varietal differences $(P=0.057)$, but this varietal effect interacted significantly with the nutrient level $(P=0.041)$. As a mean of the two years, Otira benefited significantly from the harrowing treatment (a yield increase of $4.4 \mathrm{hkg} \mathrm{ha}^{-1}$ at the low nutrient level). In contrast, for Brazil we found a marked yield reduction as a result of harrowing in the high nutrient level treatments (a yield decrease of $6.0 \mathrm{hkg} \mathrm{ha}^{-1}$ ). Due to the marked varietal differences in crop density, we tested $\Delta D$ as a covariate, but it did not significantly improve the model.

\section{Discussion}

We found a significant negative effect of pre-emergence weed harrowing on vegetation cover $(V C)$ at the high nutrient level, but no significant differences between harrowed and non-harrowed at the low nutrient level (Fig. 1). This interaction indicates that the negative effects on $V C$, which usually are observed after preemergence weed harrowing (J. Rasmussen, pers. comm.), were reduced by a compensatory positive effect at low nutrient levels in varieties like Modena and Brazil. This could be the result of breaking a crusty soil surface or increasing soil temperature, oxygen levels and nitrogen mineralization. In a study with two to three postemergence weed harrowings in spring wheat under conditions without any applied fertiliser, Steinmann (2002) concluded that post-emergence harrowing had only a minor effect on the nutritional status in the crop, but that the nitrogen content in the soil was increased significantly. We applied $40 \%$ of the optimal crop requirement (Anon, 2003) at the low nutrient level. At this level, a minor increase in nitrogen mineralization could compensate for damage caused by pre-emergence harrowing, making it a more suitable and viable practice under conditions of low versus high nutrient levels.

For Modena and Brazil, the positive effect of preemergence weed harrowing was expressed as a marked increase in crop density (Fig. 2). The varietal differences in crop density response could be caused by differences 
in speed of germination or vigour (Rasmussen \& Rasmussen, 1999), emergence force (Bouaziz et al., 1990), or in response to changes in nutrient level, aeration and temperature caused by harrowing (Steinmann, 2002). Bouaziz et al. (1990) found that a winter wheat variety had $100 \%$ emergence when obstacles (clods, etc.) below $25 \mathrm{~g}$ were removed, and the emergence reduced linearly with increasing obstacle size. The study of Bouaziz et al. (1990) included only one variety and there could have been an effect due to varietal differences in emergence force.

The marked varietal differences in resistance, measured as change in vegetation cover $(\Delta V C$, Table 3$)$, could be explained by the differences in plant height at the time of harrowing (Table 2, Fig. 3). Similarly Kurstjens and Perdok (2000) found a linear correlation between percentage coverage and plant height for ryegrass (Lolium perenne L.). Thus varieties, which are high at the time of harrowing, are more likely to resist damage caused by post-emergence harrowing, and such varieties should be chosen if weed harrowing is planned.

There was a small but significant positive correlation between the change in crop density $\Delta D$ and $\Delta V C$. The increase of 25 plants $\mathrm{m}^{-2}$ due to pre-emergence weed harrowing, found for Modena and Brazil, corresponded to an increase in coverage caused by post-emergence weed harrowing of $25 \times 0.026=0.65 \%$. This could be due to smaller and less cover-resistant crop plants in the varieties that showed an increase in crop density due to the pre-emergence harrowing treatment. Thus varieties, which are tall at post-emergence harrowing and have increased density after pre-emergence harrowing, are the ones that benefit most from weed harrowing.

We did not find any significant reduction in $L A I$ caused by harrowing in 2004, while there was a significant $9.3 \%$ reduction in $L A I$ on average in 2005 (Fig. 4). Similarly Rasmussen et al. (2004) found negative but non-significant effects on LAI. The efficacy of weed harrowing is very dependent on weather and soil conditions and differences among years are therefore also expected. We found no significant varietal interactions with weed harrowing, indicating that weed harrowing affects $L A I$ in an additive fashion.

Rasmussen et al. (2004) found that varieties responded differently to weed harrowing when measured on relative yield reduction and that the yield response was negatively correlated with parameters associated with competitive ability. The yield of high yielding varieties was affected significantly more than that of low yielding varieties. However, there was still an overall yield benefit from choosing high versus low yielding varieties, even when plots were harrowed. In that study, there was an interaction with disease severity, as mildew tended to be more aggressive in short (less suppressive) varieties. We used the absolute yield difference between harrowed and unharrowed plots, thus eliminating the possible effects of different levels of diseases. We found very different varietal responses on crop yield, as weed harrowing was significantly beneficial for Otira, while Brazil suffered from weed harrowing. Brazil tended to be the highest yielding variety under herbicide-treated, non-harrowed conditions at both high and low nutrient levels, while Otira had an intermediate yield. We found that the highest yielding varieties did not always result in the highest yield because of differences amongst varieties in their tolerance to weed harrowing.

We found that a variety with strong weed suppressive ability remains a strong weed suppressive variety, whether or not weed harrowing is used. Rasmussen and Svenningsen (1995) studied the interaction between row distance and three spring barley varieties in an experiment with no pre-emergence weed harrowings and two post-emergence harrowings with 1-month time interval. With respect to weed control efficacy, they did not find any significant interactions between variety and harrowing treatment.

Under organic or low-input growing conditions with high weed pressure, Otira would be a good choice of variety due to its strong suppressive ability, in combination with a positive response to weed harrowing and relatively high yield. In contrast, Brazil despite high yields, suffered from weed harrowing and had less weed suppressive ability. In conclusion, this study shows that the varieties differed in their response to weed harrowing in terms of yield, but not in terms of weed suppressive ability. Moreover, the yield response interacted with the nutrient level.

\section{Acknowledgements}

We thank Eugene Driessen, Karen Heinager, Henrik Grøndal and Lena Christensen for technical assistance and Kristian Kristensen for assistance with the statistical analyses. This study was granted by Danish Agricultural Research Centre for Organic Farming, DARCOF-IIVI-2, Research School for Organic Agriculture and Food Systems (SOAR) and Danish Institute of Agricultural Sciences.

\section{References}

Anon (2002) матLAв Ver. 6.5. The Mathworks Inc., Natick, MA, USA.

Anon (2003) Vejledning og skemaer 2003/04, 1-102. The

Danish Ministry of Food, Agriculture and Fisheries, Danish

Plant Directorate, Lyngby, Denmark.

Anon (2005a) http://www.aim-dtp.net/aim/digicam/dcraw/.

Anon (2005b) http://pvo.planteinfo.dk. 
Anon (2005c) http://www.sortinfo.dk.

BAERVELDT S \& AsCARD J (1999) Effect of soil cover on weeds. Biological Agriculture and Horticulture 17, 101-111.

BARBERI P (2002) Weed management in organic agriculture: are we addressing the right issues? Weed Research 42, 177-193.

Bond W \& GRundy AC (2001) Non-chemical weed management in organic farming systems. Weed Research 41, 383-405.

Bouaziz A, Souty N \& Hicks D (1990) Emergence force exerted by wheat seedlings. Soil and Tillage Research 17, 211-219.

Gundersen H, Rasmussen J \& NøRREMARK M (2006) Tolerance of cereals to post-emergence weed harrowing. In: Third International Conference on Non-Chemical Crop Protection Methods, Lille, France, 70-78.

Hansen PK, Kristensen K \& WiLlas J (2006) Forskellige sorters konkurrenceevne overfor ukrudt (Weed competitiveness of different varieties). In: Third Danish Plant Congress, Danish Institute of Agricultural Sciences and Danish Agricultural Advisory Service, Herning, Denmark, 342-343.

Jensen RK, Rasmussen J \& Melander B (2004) Selectivity of weed harrowing in lupin. Weed Research 44, 245-253.

KIRKLAND KJ (1994) Frequency of post-emergence harrowing effects wild oat control and spring wheat yield. Canadian Journal of Plant Science 75, 163-165.

KuRstJens DAG \& KropfF MJ (2001) The impact of uprooting and soil-covering on the effectiveness of weed harrowing. Weed Research 41, 211-228.

Kurstjens DAG \& Perdok UD (2000) The selective soil covering mechanism of weed harrows on sandy soil. Soil and Tillage Research 55, 193-206.

Lancashire PD, Bleiholder H, Van Den Boom T et al. (1991) A uniform decimal code for the growth stages of crops and weeds. Annals of Applied Biology 119, 561-601.

Lang ARG, XIAng Y \& Norman JM (1985) Crop structure and the penetration of direct sunlight. Agricultural and Forest Meteorology 35, 83-101.

Lemerle D, Gill GS, Murphy CE et al. (2001) Genetic improvement and agronomy for enhanced wheat competitiveness with weeds. Australian Journal of Agricultural Research 52, 527-548.

Otsu N (1979) A threshold selection method from grey-level histograms. IEEE Transactions on Systems, Man, and Cybernetics 9, 62-66.

Patterson HD \& Williams ER (1976) A new class of resolvable incomplete block designs. Biometrika 63, 83-92.

RASMussen J (1991) A model for prediction of yield response in weed harrowing. Weed Research 31, 401-408.

RASMusSEN J (1992) Testing harrows for mechanical control of annual weeds in agricultural crops. Weed Research 32, 267-274.

RASMusSEN K (2002) Influence of liquid manure application method on weed control in spring cereals. Weed Research $\mathbf{4 2}$, 287-298.

Rasmussen J \& RAsmussen K (1995) A strategy for mechanical weed control in spring barley. In: Proceedings 1995 9th European Weed Research Society (EWRS) Symposium, Budapest, Hungary, 29-37.

Rasmussen K \& Rasmussen J (1999) Barley seed vigour and mechanical weed control. Weed Research 40, 219-230.

Rasmussen J \& Svenningsen T (1995) Selective weed harrowing in cereals. Biological Agriculture and Horticulture 12, 29-46.

Rasmussen J, Kurtzmann JI \& Jensen A (2004) Tolerance of competitive spring barley cultivars to weed harrowing. Weed Research 44, 446-452.

SAS Institute Inc. (1999) SAS OnlineDoc Version 8. SAS Institute Inc., Cary, NC, USA.

STEINMANN HH (2002) Impact of harrowing on the nitrogen dynamics of plants and soil. Soil and Tillage Research $\mathbf{6 5}$, 53-59.

Welles JM \& Norman JM (1991) Instrument for indirect measurement of canopy architecture. Agronomy Journal 83, $818-825$.

Woebbecke DM, Meyer Ge, Bargen KV \& Mortensen DA (1995) Color indices for weed identification under various soil, residue, and lighting conditions. Transactions of the American Society of Agricultural Engineers 38, 259-269. 